\title{
La enseñanza del español como lengua extranjera y los torneos "Spelling Bee"
}

\author{
José Carlos Escobar Hernández,
} CEPE-Taxco

\begin{abstract}
Resumen: En esta comunicación se revisan los concursos de deletreo conocidos en los EUA con el nombre de "spelling bee", así como de la popularidad de estos certámenes en los cursos de inglés que se imparten en el CEPE-Taxco y en diversos países del mundo. Se habla principalmente de sus características, de la manera en que se organizan y se llevan a cabo los torneos, lo mismo que de las formas en que ha sido adaptado en otros países para la enseñanza de su propia lengua nacional. Se incluyen comentarios sobre el potencial que representa este tipo de torneos y de su posible adopción como parte de la metodología de enseñanza de lenguas extranjeras, particularmente del español.
\end{abstract}

Palabras clave: competencia léxica, concursos de deletreo, enseñanza de lenguas, juegos didácticos, spelling bee.

\begin{abstract}
This communication deals with the spelling contests known as "spelling bee" in the USA, as well as their popularity in the English courses taught at CEPE-Taxco and diverse countries around the world. It deals specifically with its characteristics, with the way the contests are organized and held, as well as with the ways it has been adapted in other countries to teach their own national languages. Comments about the potential these kind of contests represent are included as well as their possible adoption as part of the Foreign Language Teaching methodology, especially focused on Spanish.
\end{abstract}

Keywords: language teaching, lexical competence, spelling contests, spelling bee, teaching games.

INTRODUCCIÓN

El spelling bee es un concurso en el que los participantes deben deletrear una serie de palabras de dificultad variable y en él suelen participar estudiantes menores de 15 años en toda la Unión Americana. Se trata de una competencia en la que gana la persona o equipo que logre deletrear correctamente el mayor 
número de palabras, las cuales se seleccionan de acuerdo con diversos grados de dificultad. Si bien estos concursos ya se llevan a cabo en todo el mundo, se cree que surgieron en los EUA. Según Foxmarch (2011) el primer ganador oficial registrado fue Frank Neuhauser, quien al deletrear la palabra "gladioulus"1 ganó el primer concurso del cual se tiene memoria y que se realizó en la ciudad de Washington en 1925 cuando él tenía apenas once años de edad. Se ganó 500 dólares en piezas de oro, conoció al presidente en turno y en su ciudad de origen organizaron un desfile en su honor. Ese año marcó el inicio de estos concursos, que ahora son de carácter nacional y constituyen todo un acontecimiento dentro de la cultura educativa norteamericana, cuya instrucción escolar destaca la importancia del idioma y las matemáticas.

Históricamente (página web de Kindle) se cree que la palabra bee podría provenir del término medieval bene (Middle English, 1100-1500), que significaba "plegaria" o "favor". En Inglaterra, una forma dialectal de esta palabra es been (o vean) y se refería a la "ayuda voluntaria de los vecinos para el logro de una tarea determinada" (Webster's Third New International Dictionary). Se trata entonces de una palabra que describía un trabajo comunitario, aunque no hay una absoluta certeza en todo esto. El término se remonta con mayor claridad al año de 1850, pero el ímpetu de los torneos se debió más bien a los libros de deletreo creados por Noah Webster, los cuales fueron publicados por primera vez en 1786 y que por cinco generaciones constituyeron una parte esencial del programa de estudios de nivel primaria de los niños norteamericanos. Desde 1925 se realizan cada año, primero a nivel local y luego a nivel nacional sólo con los mejores. El premio en dinero es proporcionado por diarios que se publican en lengua inglesa y fundaciones educativas, además de que en la actualidad se transmiten porTV.

De acuerdo con Plumer (2013), este certamen es de exclusiva realización en el idioma inglés porque las palabras se escriben de una manera distinta a como se pronuncian, lo cual ciertamente es una dificultad para los hispanohablantes que aprenden esta lengua. No obstante, cuando se trata de un idioma extranjero, lo que en realidad es interesante como estrategia pedagógica es el hecho de que, por un lado, se certifica la morfología de la palabra y, por el otro, su significado o significados, además de sus usos. Por ejemplo, si el aprendiz de español se encuentra con la palabra "contento" y su maestro(a) o el diccionario le indican que esa palabra significa "happy" o "glad", puede perderse de atender a sus otros significados como "satisfecho" que en inglés se dice "satisfied", "delighted" o "pleased", cada uno de los cuales cuenta con matices propios.

1 Gladiolo, planta de tallo largo y recto con hermosas flores en espiga que también llamamos estoque por la forma que tiene (DRAE). Viene del latín gladio (espada) y ya existía en latín con gladioulus que designaba una espada corta, un puñal. 
De tal manera, al darnos cuenta de que en inglés los niños aprenden una palabra y cómo se deletrea, aunado a que durante el concurso pueden pedir el significado -si no están seguros de él- y de ahí verificar que han detectado la palabra que han de deletrear, resulta evidente que su manejo de significados constituye un manejo competente del idioma. Por ende, conviene considerar la posibilidad de llevar este procedimiento al aula de lenguas extranjeras o de segundas lenguas. No está por demás asegurarse siempre del significado de las palabras que el alumno va aprendiendo: con ello el estudiante puede incluso entender más que las meras equivalencias entre su L1 y la L2, a la par de conocer las diferencias de concepción, de ideología, de carga cultural o histórica, o matices que incluso puedan no existir en su lengua con lo que amplía su mente y su percepción de las cosas. Esto es sin duda una parte esencial del planteamiento intercultural de la enseñanza de lenguas.

Desde esta perspectiva, el spelling bee constituye una manera muy concreta de aprender y dominar el significado de los vocablos y así lograr una competencia léxica que le servirá en la expresión oral y escrita del aprendiente; sólo así podrá hablarse de una verdadera adquisición y dominio de la L2. En los concursos que organizan los maestros de inglés en el CEPE-Taxco puede observarse claramente -como efecto colateral- que todos los estudiantes, sin excepción, concretamente los que no se atrevieron o no pudieron participar como figuras centrales en la competencia, participan activamente en silencio durante todo el concurso, respondiendo también en silencio y desde sus asientos, aunque a ellos no se les haya pedido el deletreo de las palabras. Ocurre algo similar en los concursos de televisión que prueban los conocimientos de los concursantes relacionados con los conocimientos y cultura general y el público participa con los concursantes desde su casa. Aparentemente, el buen nivel con el que egresan estos alumnos ha dado un gran prestigio a las clases de inglés que se imparten en dicho plantel.

\section{EL JUEGO EN LA ENSEÑANZA DE LENGUAS EXTRANJERAS}

Con el abandono de la metodología tradicional, la década de los setentas representa una década de progresos y novedades en lo referente a la enseñanza de lenguas extranjeras. Ello ha quedado demostrado por el surgimiento de planteamientos como el de la Respuesta Física Total, el Enfoque Natural, la Sugestopedia, e incluso el del propio Enfoque Comunicativo, que formaron parte de la revolución cognitiva en un panorama compuesto por modelos como el innatismo, el generativismo (Chomsky) y el constructivismo (Piaget) para responder a las limitaciones de los métodos anteriores, sobre todo 
a la concepción conductista del aprendizaje. Aunado a ello, aparecieron libros dedicados a la enseñanza de cada una de las habilidades o destrezas comunicativas y así surgieron textos que analizaban en profundidad los problemas, retos y posibles soluciones para ayudar al desarrollo de la destreza lectora, de la producción oral, de la escritura y de la pronunciación. Con el fin de dar variedad y agregar un elemento lúdico a la clase surgieron textos dedicados a sugerir y proponer el empleo de juegos diversos para ser utilizados como una herramienta eficaz en el aprendizaje de lenguas.

De tal suerte, diversas universidades se dieron a la tarea de publicar libros que constituían las llamadas "bibliotecas del profesor", en las cuales los maestros de inglés principalmente podían encontrar un sinnúmero de sugerencias e ideas que podrían utilizar en sus clases. Un ejemplo de ello fue el libro de W.R. Lee, Language Teaching Games and Contests (1965), quien celebraba el hecho de haber dejado atrás la desconfianza e incredulidad de los maestros respecto del empleo de juegos que cualquier niño jugaba -como el de "víboras y escaleras", los crucigramas y muchos otros- dado que en aquél entonces los expertos debatían sobre la diferencia entre "trabajo" y "juego" dentro del salón de clases. Pero, como concluyera dicho autor, cuál puede ser en realidad la diferencia entre trabajar y jugar cuando se considera que en ambas actividades la persona se enfrasca por completo en una actividad en la que pone todo su esfuerzo y atención.

Así fue como en su momento se puso de moda hablar de juegos, juegos que sin duda muchos han usado o siguen usando y que ayudan a romper el hielo, a integrar a los alumnos, a vencer temores y barreras de participación, etc. Hay que recordar que en aquel entonces se hablaba en específico de: juegos orales, de pronunciación, de lectura y juegos orientados hacia la redacción, además de los diseñados para aprender a deletrear. De tal suerte llama la atención el concurso del spelling bee que puede ser visto como un juego que divierte pues, si bien es un concurso muy serio y severo, no por ello deja de causar la emoción propia de todo torneo como actividad en la que se pone un cabal esfuerzo para tratar de ganar. En este sentido es propiamente un deporte.

Cabe recordar que en términos generales el vocabulario se enseña de muy diversos modos, a saber:

1. Llamando la atención sobre una nueva palabra -lo cual puede significar: (a) que es, puede o debe de ser de su interés general o particular; (b) que es de interés para la lectura en clase o para su cultura general; (c) que se va a emplear en una conversación o ejercicio determinado; (d) que es de uso frecuente, o bien (e) que es de uso general, técnico, poético o coloquial. 
2. Dejando que los alumnos la reconozcan; es decir: (a) que la vean en todos los contextos posibles o en la mayoría de ellos; (b) que las encuentren en textos de su interés; (c) que les sean pedidos en la escuela, como parte del contenido de sus materias; (d) que sean frecuentes en la vida cotidiana, o bien, (e) que sean empleadas en los diarios, revistas y demás medios de comunicación.

3. Pidiéndoles que la usen por sí mismos (producción / creatividad)

Existen muchos juegos: los alumnos pueden llenar espacios en blanco, formar palabras en scrabble, ${ }^{2}$ o bien trabajar con las raíces de los vocablos, lo mismo que trabajar con prefijos, afijos y sufijos para ver la relación que el léxico guarda en sí mismo (derivación), siempre con un sentido didáctico y lo más realista posible y de manera individualizada, que se refieran a cosas personales, a algo que ellos quieran o necesiten decir, que conozcan, para que no sufran con algo que no conocen o les disgusta y que fácilmente pueden olvidar.

Otra manera de aprender las palabras es describiéndolas. El objetivo del juego es hacer que los jugadores adivinen alguna, a veces dejando de mencionar alguna que pueda dar una clave demasiado evidente. Por ejemplo, si tiene que adivinar la palabra "rojo" no puede decir que se trata de un color. Antes de jugar hay que asegurase de darles las frases que podrán usar para describir su significado. Por ejemplo: "Se usa para / en / con....; ;" Lo encuentras en..."; "Hacemos esto cuando...", etc. Se puede obtener el juego para usarlo con los estudiantes o se puede crear uno propio con las palabras que los alumnos hayan aprendido recientemente o en las que los profesores(as) deseen enfocarse.

Otros juegos son:

a) El propio spelling bee pues se entiende que ayuda a deletrear y a revisar palabras contenidas en las listas de vocabulario de los cursos impartidos. En el CEPE-Taxco, los maestros que organizan el torneo dividen a sus grupos y les preguntan por el deletreo y la definición de palabras. El equipo que más acierte, gana.

b) Encontrar las vocales. En este se emplean tarjetas que contienen palabas a las que les falta una, dos o tres vocales y en otras tarjetas las vocales que

2 El scrabble suele ser considerado el rey de los juegos con palabras. En este juego tradicional, los jugadores tienen que formar palabras para anotar puntos. Pueden obtener más puntos al usar letras menos frecuentes (como la Q y la Z) o al jugar con sus dados de maneras que les dan dobles puntajes. Al jugar scrabble con aprendientes de inglés se les puede permitir emplear el diccionario o un buscador de palabras durante el juego. Sin embargo, antes de jugar con una palabra deben poder decirla y darle un significado. Esto asegura que la palabra exista y no inventen. 
faltan sin las que se presentaron en las primeras. Por ejemplo: $C A-Z A$ / --BE-- / = CABEZA. Se recomienda agregar tantas tarjetas como sean necesarias y que correspondan al vocabulario visto a lo largo del curso.

c) Otro gran juego es el de la lotería, el cual puede cambiar conforme los alumnos aprendan nuevas palabras. Se canta la definición y los alumnos marcan la tarjeta si la tienen. El primero en terminar gana (como en la lotería tradicional).

d) Se puede hacer por temas, por contenidos gramaticales, por colocaciones, etc. Por ejemplo basado en las colocaciones sería el siguiente, en el cual se trabaja con adjetivos + sustantivos:

\begin{tabular}{l|l|l|l|l} 
Delicioso & curry & café & comida & aroma \\
Desabrido & bebida & ropa & corbata & habitación \\
Dulce & vino & momento & música & voz \\
Amargo & bebida & café & experiencia & té \\
Caliente & café & tarde & comida & habitación \\
Cálido & música & abrazo & ambiente & risa \\
Frío & saludo & sopa & día & mensaje \\
Fresco & ropa & agua & música & concierto
\end{tabular}

Cualquier juego en el que se presenten nuevas palabras acompañadas de su correspondiente explicación será bueno, pero es necesario que el alumno también aprenda la explicación del maestro a fin de conocerlas a fondo. Por ejemplo: wet, damp, humid y moist: (a) humid se usa para referirse a un clima o aire húmedo que nos hace sentir incómodos; (b) damp se refiere a algo ligeramente mojado que produce incomodidad, como una camisa o un pantalón que no se ha secado; (c) moist se refiere a algo ligeramente húmedo que causa placer, implica una menor cantidad de agua, por ejemplo, en una toalla para limpiar la cara, un pastel que no es seco, y (d) wet conlleva la idea de mucha agua y se usa para describir superficies mojadas como el piso, la ropa bajo la lluvia, el cuerpo al salir de la ducha).

Diferencias semejantes se encuentran detrás de los verbos to wait, to expect, to hope: "I am waiting for you at the airport, expecting you to show up but hoping you won't come", que en español no se diferencian morfológicamente pues decimos "Te estoy esperando en el aeropuerto; espero que aparezcas pero que no llegues." 
En cuanto a los juegos para aprender a deletrear y pedir a los alumnos que escribieran lo que se les dictaba, lo que escucharan, llama la atención que no estuvieran incluidos los lineamientos o adaptaciones del spelling bee. Ello tal vez se debió a que en realidad nunca se vio como un juego sino como una forma seria y competitiva de aprender palabras y conceptos principalmente.

Entonces, ¿por qué interesa a la enseñanza de lenguas? Porque una parte de la actividad cotidiana del profesor(a) es llamar la atención sobre las palabras y sus definiciones, y señalar -en lo general- si pertenecen al habla coloquial, formal, técnica o figurada, o si son palabras que algún día podrían utilizar. De tal suerte, una manera de asegurar que el alumno se enfrasque en su aprendizaje, con toda exactitud y a profundidad, es precisamente con este tipo de torneos que podrían llevarse a cabo entre diferentes grupos de un mismo nivel, para demostrar el manejo o competencia léxica del aprendiente. Si bien no se pretende que los alumnos de distintas escuelas compitan entre sí-como se hace en los EUA-, en el CEPE-Taxco se pone a competir a los alumnos de niveles similares.

El procedimiento que siguen los profesores de inglés en dicho plantel consiste en pedir a los competidores que deletreen una amplia selección de palabras, generalmente en diversos grados de complejidad, de acuerdo con su nivel de aprendizaje y los contenidos de sus cursos. El procedimiento del concurso es interesante pues el competidor puede no escuchar con claridad, momento en el cual pedirá que se le repita o se le aclare mediante la definición, algo que se hace a nivel de habla real cuando desconocemos las palabras y conceptos, sea que los escuchemos en la escuela, en alguna materia específica o incluso en una lectura, que es cuando acudimos al diccionario para ver la definición.

En el caso del español como lengua extranjera, y dado que el español es mucho más regular en la manera en que se escriben las palabras, el torneo podría adaptarse de modo que algunas veces se le diera al alumno la definición para que él recuerde la palabra y entonces la deletree o bien hacerlo a la inversa para darle la palabra y que él proceda a dar su definición (o alguna que conozca). De cualquier forma, estaría demostrando su competencia léxica.

\section{EL SPELLING BEE Y LA COMPETENCIA LÉXICO-CONCEPTUAL}

Los americanos consideran el spelling bee como un viaje lleno de trabajo duro, determinación y la oportunidad de hacer prolongadas amistades y gratos recuerdos que van del salón de clases a la cafetería, del auditorio al centro cívico, en un torneo que se ha vuelto una tradición y cuyo propósito es ayudar 
a los estudiantes a mejorar su ortografía, incrementar su vocabulario, aprender conceptos y a desarrollar un uso correcto del vocabulario que les será de mucha ayuda a lo largo de su vida.

Como muestra de lo que se hace a nivel mundial con el spelling bee, el cual parece ser una estrategia común en el aprendizaje del idioma inglés, en la Wikipedia se reporta, a manera de ejemplo, que:

- En la India, la competencia exige aprender la ortografía correcta de las palabras, su empleo en oraciones y en múltiples contextos.

- En África participan niños de 7 a 16 años de edad, en todo el continente (Uganda, Kenya, Sudáfrica, Etiopía, Zimbawe, y Nigeria).

- En Australia, entre niños de $5^{\circ}, 6^{\circ}, 7^{\circ}$ y $8^{\circ}$ grado se emplea una modalidad en línea para las etapas eliminatorias y la final se lleva a cabo ante un público. Se premia semanalmente a los alumnos y también a los maestros que más hayan mejorado.

- En Canadá se realiza desde 2005 y en Kuwait realizaron el primer concurso a manera experimental en su escuela, el cual fue todo un éxito y por lo cual se decidió llevarlo a sus distritos escolares. Lo mismo sucede en el CEPE-Taxco, donde se realiza este concurso y los alumnos demuestran su domino del léxico del idioma inglés.

Al nivel más elemental, los alumnos estudian el léxico que aparece tanto en sus cursos como en los ejemplos y lecturas que sirven para hablar y escribir. Por tanto, aprenden conceptos conforme a su nivel y nunca al azar. Más aún, en lo que se refiere al aprendizaje de la lengua nacional, resulta interesante ver lo que hacen otros países para la enseñanza-aprendizaje de su propia lengua. Por ejemplo, llama la atención lo que hacen los chinos y los japoneses:

a. De acuerdo con Mair (2013) y Tsai (s/f) en China se realiza una competencia de dictado de caracteres que se transmite por TV y en el cual los competidores tienen que escribir los caracteres que se les dictan. Se trata de un concurso inspirado en el spelling bee norteamericano.

b. Por su parte, los japoneses hacen algo similar, el kanji kentei, una prueba de aptitud en el conocimiento de los kanji que es organizada por una fundación denominada Japan Kanji Aptitude Testing Public Interest Foundation. 
Según la Wikipedia, los japoneses tienen 12 niveles de dificultad que van del nivel 10 (el más fácil) al nivel 1. Esta prueba examina no sólo la capacidad para leer y escribir los kanji sino que además examina la capacidad de entender su significado, su empleo correcto en oraciones e identificar el orden correcto de sus trazos. Aunque originalmente fue creado para hablantes nativos, los hablantes de otras lenguas también pueden tomar este examen. El nivel 1 es tan difícil que son muy pocos los que lo toman y lo pasan pero lo toman desde los niños de kínder hasta los universitarios y adultos en general. A los niños de 7 años se les examina con los 80 primeros kanji que aprenden, luego en primaria y secundaria aprenden los siguientes 240 , y así sucesivamente hasta llegar al nivel 1, en el cual se prueba:

1. su capacidad para leer y escribir los 6355 kanji de los niveles 1 y 2 en sus dos lecturas, la china y la japonesa,

2. requiere el uso en oraciones y seleccionar el más adecuado a un contexto dado,

3. prueba también lecturas de kanji que son especiales o inusuales,

4. prueba el conocimiento de ateji o"letras asignadas", que son: (a) las maneras de usar un kanji en las que o bien el significado o la lectura no les es propia pero sirve para representar palabras extranjeras como "kohi" (café), que se escribe con kanji que representan otra cosa ya que significan "aguja para el pelo" y "collar de perlas" o bien, (b) que se emplean por su significado pero son leídos "a la extranjera", como tabako, que se escribe con los kanji que representan humo y hierba ( 煙草, “humo"+"hierba”) y debería leerse ensō. Aunque ambos tipos de ateji están en desuso, ya que en ambos casos se utiliza más el silabario katakana. De hecho, es muy difícil ver actualmente 珈琲 o 煙草 por Japón, y en su lugar lo habitual es コーヒーyタバコ.

5. prueba el conocimiento de sinónimos y antónimos,

6. prueba la capacidad para diferenciar entre homónimos,

7. prueba palabras compuestas especiales,

8. prueba los radicales complejos,

9. prueba los kanji que son exclusivos de la lengua japonesa y no tomados de China,

10. prueba los proverbios clásicos japoneses y las expresiones idiomáticas,

11. prueba los nombres de lugares y países,

12. prueba la capacidad para reconocer la relación entre las formas actuales y las antiguas de los kanji. 
Evidentemente, la consideración de este panorama mundial relacionado con el éxito y la difusión lograda por el spelling bee como estrategia de enseñanza del inglés -e incluso por lo que se hace con la lengua nacional de los países antes mencionados- lleva a considerar por qué no se ha implementado en México como parte de la formación escolar en lengua española. Por otra parte, respecto de la enseñanza de E/LE, la importancia del spelling bee se comprueba al ver el nivel de dificultad en el deletreo de palabras del español que son un reto no únicamente para un extranjero sino también para los propios hispano-hablantes como cuando se ven en la circunstancia de escribir palabras como: "abscisa", "abrazadera", "acabose", "acepción", "adhesión", "advenedizo", "agazaparse", "agüita”, "ahuyentar", "alcahuete", "alvino", "atraso", "atravesar", "azahar" ,"bahía”, "bajeza”, "bizcocho", etc., aunado al problema de su correspondiente definición, precisión semántica, usos y sentidos posibles.

Según Perasso (2011), en los EUA ya se cuenta con una versión hispana del spelling bee, la cual es muy popular entre los estudiantes estadounidenses. Según la autora, la versión española del concurso habla del carácter multicultural de la sociedad estadounidense y constituye un reconocimiento del carácter multilingüe de los Estados Unidos. Sin embargo, pese a que la Ley de Educación Bilingüe está vigente desde 1968, con modificaciones sucesivas, los docentes señalan que en el ámbito escolar no siempre resulta sencillo promover el idioma. En palabras de Mayra Sánchez, maestra primaria en un barrio de mayoría hispana del sureste de Los Ángeles citada por Perasso (o.c.):

\footnotetext{
“Para los niños hispanos, aprender inglés es una necesidad de integración. Por eso es bueno que existan estas iniciativas populares, que les hacen ver que su idioma vale tanto como el nuevo y hará que los hispanos de segunda o tercera generación tengan interés en no perder el idioma de la casa".
}

De acuerdo con Briceño, citado por Perasso (o.c.), su valor pedagógico consiste en contar con un repertorio de palabras del castellano, que les permita enunciar con precisión cada letra de acuerdo con el carácter morfo-fonémico del idioma que permite escribirlas como se dicen, lo que según Briceño no quita interés al spelling bee en la lengua de Cervantes porque, además del reto que representan los acentos, las "eses“ y "zetas", no se trata sólo de conocer los fonemas sino de saber otras reglas del idioma. Sánchez, citada por Perasso (o.c), agrega:

"Lo más importante es que (el concurso) da a los niños una comprensión del origen de las palabras, permite aumentar el vocabulario y aprender conceptos".

Lo anterior se aplica tanto a los hispanos de nacimiento como a quienes estudian español como segunda lengua. Lo que hace difícil el concurso serán las palabras de orígenes tan distintos como el griego, el germano, el anglo y 
todos los idiomas de los cuales se ha nutrido el español, exactamente como sucede con el inglés y que de cualquier manera resulta poco transparente para los alumnos asiáticos (Japón, China y Corea), quienes sólo tendrán ventaja si antes del español ya han aprendido inglés o alguna otra lengua romance, lo cual también será un problema por la interferencia no sólo en la ortografía sino en los conceptos que, como hemos señalado, no siempre se corresponden o existen en una lengua y otra.

\section{EL PAPEL DE LA MEMORIZACIÓN}

El spelling bee es un juego que valora mucho la memorización, algo que los sistemas educativos contemporáneos han dejado de lado o que contemporáneamente se critica en reformas educativas actuales como la de México. Memorizar resulta clave para la buena ortografía y si sirve para eso también ha de servir para muchas otras cosas, ya que requiere de esfuerzo y estudio hasta lograr el aprendizaje del significado de palabras que tal vez nunca antes se habían oído. Si bien puede ser fácil deletrear "filtro", "riqueza" o "amo", la competencia se intensificará a la hora de desglosar letra por letra palabras como "enviscar" ("recubrir algo con una sustancia viscosa"), "bacteriolítico" ("que produce la disolución de las bacterias), "sanctasanctórum" (parte más oculta y reservada de un lugar), "ranunculáceo" (de hojas alternas y generalmente divididas) o "Tenochtitlán", palabras que forman parte del compendio de términos con el que se pueden medir las habilidades ortográficas de los alumnos no solamente mexicanos sino también los que aprenden español.

Hay que anotar la presencia en todo esto de un aspecto sumamente importante: el papel que desempeña la memoria, uno de los principales procesos cognitivos con los que contamos. Cabe anotar que, en general, el término memoria según Ch. Kekenbosch (1996:06), citado por Piserra Bolaños (2017), se utiliza para designar una facultad mental que permite conservar en la mente una determinada cantidad de datos, siendo una de sus propiedades esenciales la de poder acceder a ellos, además de contar con procesos de codificación, de almacenamiento y de recuperación. Estas propiedades tienen importancia evidente en el aprendizaje de lenguas extranjeras, a pesar de lo cual, según Jiménez (1997), citado por Rodríguez Méndez (2013), ha sido olvidada en numerosas ocasiones por los autores de muchos manuales que se limitan a citar elementos como la inteligencia, la personalidad o la motivación como partes integrales de la teoría del aprendizaje.

Los mecanismos de la memoria, en cuanto al proceso de memoria sensorial auditiva, al proceso de recuperación de la memoria semántica y al rendimiento, 
tienen que ver con la memoria y el aprendizaje de una lengua que ha de llegar al nivel de adquisición y desempeño. Resulta innegable que el aprendiente de una lengua tiene que memorizar acentos, tonos, ritmos, articulaciones, entonaciones, lo mismo que significados, usos y definiciones, además de reglas gramaticales y aspectos sociales y culturales. ${ }^{3}$ Justo un ejemplo de estos procesos de memoria son los que permiten que el alumno recuerde tanto el significado de los adjetivos como de las palabras a las que pueden acompañar, las colocaciones (véase la Tabla 1). Es por ello que el concurso del spelling bee se vuelva tan pertinente para los profesores de lenguas vivas.

\section{CONCLUSIÓN}

El spelling bee es mucho más que un juego: es un trabajo sesudo y formal que al final termina en una competencia abierta que beneficia incluso a todos los presentes al participar junto con los competidores de una manera silenciosa. Es un juego que ha sido llevado a la TV en todos esos programas de concurso donde hay que definir palabras y hablar de hechos de todo tipo.

En el caso de los alumnos que aprenden inglés en el CEPE Taxco, se puede ver que estos concursos son enormemente beneficiosos para ellos: se observa un gran avance y un sorprendente manejo preciso de muchas palabras que aprenden en sus cursos. Como se ha comentado aquí, se trata de un juego que les sirve y les servirá toda la vida pues atiende un aspecto importante: la comunicación precisa de lo que piensan y de lo que quieren decir o expresar, ¿qué más se puede pedir en un alumno?

Me parece que, más que una competencia, el torneo spelling bee constituye una demostración fehaciente del conocimiento de la lengua, de sus cambios de forma y de los conceptos que es capaz de expresar, con todo y su significación, usos y referentes culturales de la comunidad que la habla. De tal suerte, me parece que sería muy conveniente pensar en la implementación de este tipo de concurso tanto en las escuelas del país, para todos los grados escolares, como en las clases de español para extranjeros.

Se trata de un ejercicio concienzudo de aprendizaje de la lengua que no ha sido considerado por ningún planteamiento o enfoque ni por ninguna metodología, al menos en lo que se refiere a los enfoques más conocidos, populares y de mayor difusión. Son muchos los aspectos relacionados con el

3 Según Piserra (o.c: 699), los psicólogos cognitivos afirman que la memoria de corto plazo (de trabajo) se emplea al tener que repetir una palabra nueva y que la de largo plazo (episódica y semántica), se activa en las actividades de producción oral y escrita por referirse a la experiencia acumulada por la persona. 
aprendizaje de una lengua extranjera: las colocaciones, la selección y precisión léxica, la comprensión de conceptos que surgen en la lectura, etc. De tal suerte, no hay duda de que el empleo amplio y preciso del vocabulario es sumamente beneficioso en la vida del hablante, totalmente útil en su comunicación cotidiana y particular en todos los ámbitos de su vida, sean éstos la familia, la escuela o el trabajo. Por ende, sería bueno considerar la posibilidad de implementar el uso del spelling bee en los cursos de español para extranjeros. 
REFERENCIAS

LeE, W.R. (1965). Language Teaching Games and Contests. A teachers library. Oxford: Oxford University press.

\section{REFERENCIAS ELECTRÓNICAS}

Busy teacher. Sitio para maestros de lengua inglesa. Apartado relacionado con los juegos empleados en la enseñanza. Recuperado el día 12 de septiembre de 2017 en: http://busyteacher.org/

Curiosidades: Los concursos de spelling bees. Recuperado el 12 de mayo de 2017 de http://whatsup.es/blog/curiosidades-los-concursos-de-spelling-bees

Foxmarch, M. (2011). Frank Neuhauser, a Speller's Speller, Dies at 97. Recuperado el 24 de agosto de 2017 de: http://www.nytimes.com/2011/03/23/ us/23neuhauser.html?_r=1

Kindle / Scripps. Página web oficial de los concursos spelling bee. Recuperado el 17 de agosto de 2017 de: http://spellingbee.com/origin-term-spelling-bee

MAIR, V. (2013). Spelling bees and character amnesia. Artículo recuperado el 10 de septiembre de 2017 de: http://languagelog.ldc.upenn.edu/nll?p=5669

Perasso, V. (2011). "Spelling Bee" se vuelve hispano. Recuperado el 30 de mayo de 2017 de: http://www.bbc.com/mundo/noticias/2011/07/110707_ spellingbee_hispano_nvo-mexico_cch.shtml

PISERRA Bolaños, Ma. P. (s/f). El proceso de la memoria en relación con la enseñanza / aprendizaje del francés como lengua extranjera. Universidad La Rioja. Recuperado el 02 de octubre de 2017 de: https://dialnet.unirioja.es/ descarga/articulo/1011638.pdf

Plumer, B. (2013). Spelling bees are only fun in English. So here's what other countries do instead. Recuperado el 12 de septiembre de 2017 de: https:// www.washingtonpost.com/news/wonk/wp/2013/05/30/spelling-beesare-only-fun-in-english-heres-what-other-countries-do-instead/?utm _ term $=.433593 \mathrm{a} 5 \mathrm{ca} 03$

Rodríguez Méndez, S. (2013). El papel de la memoria en el aprendizaje de una segunda lengua. Universidad La rioja. Recuperado el 2 de octubre de 2017 de: http://reunir.unir.net/bitstream/handle/123456789/2086/TFM_Silvia_ Rodriguez_Mendez.pdf?sequence $=1$ 
Wikipedia. Spelling Bee. Recuperado 2l 24 de agosto de 2017 de: https:// en.wikipedia.org/wiki/Spelling_bee

TsAl, M. (s/f). Bees Overseas. How do spelling contests work in other countries? Recuperado el 18 de junio de 2017 de: http://www.slate.com/articles/news_ and_politics/explainer/2007/05/bees_overseas.html 
